\title{
The Realization of Interpersonal Meanings in the Discourse of Abdul Qodir Jaelani
}

\author{
Ahmad Yusri \\ Study Program of English Language Education, STKIP Hamzanwadi Selong
}

\begin{abstract}
The present study deals with the realization of interpersonal meanings in the discourse of Abdul Qodir Jailani (AQJ). The aims of this study were to explain the mood, modality, and appraisal systems which are realized in the discourse of AQJ. It used a descriptive qualitative research in the form of discourse analysis. The results uncover that each domain of those three linguistic evidences had its proportion. First, the realization of Mood systems for the four texts was demanding goods and services especially the spoken texts and giving information. Second, the use of modality system was a high proportion that was found in text 1 . However, a slight proportion was found in text 2 , text 3 , and text 4 . Third, the realization of appraisal system showed the speakers and the writers feeling on the event including their appreciation, affect, judgment, and amplification. Deeply, it is suggested to conduct further study to create intelligible language in teaching, to make a critical thinker of students, and to produce the best understanding of social practices of the way people do.
\end{abstract}

Key Words: AQJ; Discourse; Interpersonal Meanings

\section{Introduction}

Social life is the values and beliefs which are done by a group of people. By nature, social life is tied to fundamental features of such arrangements, (Theodore, 2002). To do social life is mostly influenced by economic domain. It influences rules in society including policy issue of educational career, politic, entertainment, and crime. For example, the accident of Abdul Qodir Jailani (AQJ) is as the prime suspect of a deadly pile-up causing six deaths and passengers were suffered injuries of cashing cars lately, (http://news.detik.com/read/2013/ and www.thejakartapost.com.html).

The event was based on the quality of educational background of the suspect. It means that there is a problem in practicing social interaction. Moreover, it is dealing with language especially English. This language construes viewpoints of discourse happened in society. The study of discourse is the study of language use, (Fasold, 1990 as cited in Schiffrin, et al, 2001). 
In discourse study, it deals with text and context. The two terms 'text' and 'context' have a particular significance in systemic theory, (Christie, 2002). Text is the socially and contextually complete unite of language, which may be written or spoken, preferably from the beginning to the end, (Eggins, 1994). Contexts impact on the way we produce and interpret texts, (Thornbury, 2005). These automatically deal with interpersonal meanings.

Interpersonal meanings may be said to function 'prosaically', operating fluidly throughout the text, (Christie, 2002). It means in analyzing texts, society particularly students will go with interpersonal meanings in which they become a manner to obtain aims of communication in interaction in social practices such as asking and telling. Besides, this knowledge drives to deal with grammar which is applied beyond the clauses or texts. Additionally, Interpersonal meanings have three systems that are mood, modality, and appraisal systems (Freddi, 2004).

Regarding to the issue of AQJ, it was essential to conduct a study on the notion of interpersonal meanings, in which it was entitled, "The Realization of Interpersonal Meanings in the Discourse of Abdul Qodir Jailani (AQJ)." The research questions were to 1) How is the mood system of the texts realized in the discourse of AQJ?, 2) How is the modality system of the texts realized in the discourse of AQJ?, and 3) How is the appraisal system of the texts realized in the discourse of AQJ? Meanwhile, the aims of the study were to describe and to explain the interpersonal meanings including mood, modality, and appraisal systems realized in the discourse of AQJ.

Hopefully, by conducting this study, it would be useful to make society especially to produce creative students of university students in obtaining their source of learning as authentic material particularly in implementing the paradigm of discourse analysis. Others, this study is convenient to make readers aware on problems without teaching them, to lead readers to read they need and to discuss what to discuss, and to get humble and tolerant. Deeply, it is extremely significant in education especially for English learners of non-native speakers.

\section{Method}

The issue of this study was the discourse of AQJ that was spoken and written texts. There were four texts including two spoken (text 1 and text 2) and two written texts (text 3 and text 4 ). The both texts of news of AQJ were analyzed by discourse analysis paradigm. This discourse analysis was interpersonal meanings which consist of the mood, modality, and appraisal systems. They were adopted from Eggins (1994, 2004), Eggins and Slade (1997), Freddi (2004), Gerot and Wilgnell (1994), Halliday and Matthiessen (1999), Martin and Rose (2003), and Palmer (1986). It focused on the interpersonal meanings between the speakers and the addressee. Moreover, it was descriptive qualitative research which basically had a purpose to describe a particular event. Qualitative research is interpretive research and is descriptive in that the researcher is interested in process, meaning, and understanding gained through words or picture, (Creswell 1994: 145-7).

The techniques of choosing the data were to observe and to decide the most popular event nowadays in society by means of the event never happened previously. It of course 
was impact for society in undertaking social practices. Furthermore, the variables that analyzed in this study were both spoken and written texts on the discourse of AQJ.

Moreover, the procedures of data collection were: 1) the researcher decided the boundaries for the study that was the texts of news of AQJ cited on online electronic Jakarta Post and social media such as YouTube; 2) next, the researcher collected the texts; 3) then analyzed them based on the method of data analysis, discourse analysis; and 4) interpreted the data based on the unit of analysis, interpersonal meanings.

Last, in order to obtain the purpose of the study, there were two instruments of data collection including grammar analysis and lexical analysis. GRAMMAR analysis, firstly, consists of two components: mood system and modality system. First, MOOD system consists of imperative and indicative: declarative and interrogative. Interrogative consists of Yes/No polar and Wh-content. The second is MODALITY system. Its components are modulization and modulation. Modulation consists of obligation, inclination, and capacity. Then, modulization consists of probability and usually. Secondly, instrument of data collection is Lexical Analysis. It is APPRAISAL system. Here, this system consists of four categories including appreciation, judgment, affect, and amplification. Additionally, the form of data was percentage $(\%)$ in order to illustrate then interpret the findings.

\section{Findings and Discussion}

In the research findings, it consists of the realization of interpersonal meanings. They are mood, modality, and appraisal systems. It was taken from both text types of spoken and written. They were the comments (text 1 and text 2) and the news (text 3 and text 4) of collision of $A Q J$.

\section{The Realization of Mood System in the Discourse of AQJ}

Discussing about Mood system, there are two components existed in the discourse of AQJ. They are mood clause structures and MOOD block and RESIDUE. In it analysis, there are two crucial fields to analyze in order to realize the clauses' function either proposals (offer and demand) or proportions (giving information).

\section{Mood clause Structure}

The realization of mood clause structure in the comments and the news reports on AQJ, it is shown in table 1.

Table 1 Mood Clause Structure Analysis

\begin{tabular}{llcccc}
\hline \multirow{2}{*}{ Mood Clauses } & \multicolumn{4}{c}{ Percentage } \\
\cline { 2 - 5 } & & Text 1 & Text 2 & Text 3 & Text 4 \\
\hline Full Dec. & $78(71 \%)$ & $98(72 \%)$ & $24(92$ & $32(91 \%)$ \\
$\%$ & & & $\%)$ & \\
\cline { 2 - 6 } Elliptical Dec. & & $11(10 \%)$ & $16(12 \%)$ & $1(3 \%)$ & $2(6 \%)$ \\
Interrogative & Yes/No Polar & $1(1 \%)$ & $3(2 \%)$ & $0(0 \%)$ & $0(0 \%)$ \\
\cline { 2 - 6 } & $\begin{array}{l}\text { Elliptical Yes/No } \\
\text { polar }\end{array}$ & $0(0 \%)$ & $1(1 \%)$ & $0(0 \%)$ & $0(0 \%)$ \\
\cline { 2 - 6 } & Wh-Content & $1(2 \%)$ & $10(7 \%)$ & $0(0 \%)$ & $0(0 \%)$ \\
\hline
\end{tabular}




\begin{tabular}{rlcccc}
\cline { 2 - 5 } Imperative & Command & $3(3 \%)$ & $1(\%)$ & $0(0 \%)$ & $0(0 \%)$ \\
\cline { 2 - 6 } & Elliptical Command & $0(0 \%)$ & $2(\%)$ & $0(0 \%)$ & $0(0 \%)$ \\
\cline { 2 - 6 } & Suggestion & $11(11 \%)$ & $5(4 \%)$ & $1(3 \%)$ & $0(0 \%)$ \\
\cline { 2 - 6 } & Elliptical sug. & $5(4 \%)$ & $0(\%)$ & $0(0 \%)$ & $1(3 \%)$ \\
\hline
\end{tabular}

Moreover, regarding to the data shown in table 1, it comprises of four texts. For text 1 and text 2 are adopted from spoken texts which are transcribed into written forms as spoken texts. Besides, text 3 and text 4 are taken from electronic Jakarta Post as written texts. Besides, concerning on the data findings, in text 1 and the viewpoint of on the use of full and elliptical declarative that, firstly, the highest percentage of the usage of all clauses is full declarative, and its percentage is $71 \%$. There are some examples full and elliptical declarative.

\section{MOOD block and RESIDUE}

The second domain analysis of Mood system is MOOD block and RESIDUE. This identified 'subjects' of and these are illustrated based on each part of MOOD and RESIDUE.

Table 2 Subject Analysis of MOOD Block Analysis

\begin{tabular}{|c|c|c|c|c|c|}
\hline Type & Iood Block & Text 1 & Text 2 & Text 3 & Text 4 \\
\hline \multirow{14}{*}{ Subject } & I & $6(5 \%)$ & $21(15 \%)$ & $0(\%)$ & $0(\%)$ \\
\hline & You & $1(1 \%)$ & $0(0 \%)$ & $0(\%)$ & $0(\%)$ \\
\hline & They & $1(1 \%)$ & $5(4 \%)$ & $0(\%)$ & $1(3 \%)$ \\
\hline & $\mathrm{We}$ & $11(10 \%)$ & $11(8 \%)$ & $0(\%)$ & $0(\%)$ \\
\hline & She & $0(0 \%)$ & $1(1 \%)$ & $0(\%)$ & $0(\%)$ \\
\hline & $\mathrm{He}$ & $7(6 \%)$ & $5(4 \%)$ & $4(15 \%)$ & $2(6 \%)$ \\
\hline & It & $4(5 \%)$ & $0(0 \%)$ & $1(4 \%)$ & $1(3 \%)$ \\
\hline & $\begin{array}{l}A Q J / \text { the } \\
\text { Child/Son }\end{array}$ & $4(5 \%)$ & $2(1 \%)$ & $3(11 \%)$ & $1(3 \%)$ \\
\hline & Parent(s) & $1(1 \%)$ & $2(1 \%)$ & $3(11 \%)$ & $0(0 \%)$ \\
\hline & Who & $3(3 \%)$ & $2(1 \%)$ & $0(\%)$ & $2(6 \%)$ \\
\hline & That & $23(21 \%)$ & $36(27 \%)$ & $3(11 \%)$ & $5(14 \%)$ \\
\hline & Which & $0(\%)$ & $0(\%)$ & $0(\%)$ & $1(3 \%)$ \\
\hline & Victim & $0(\%)$ & $0(\%)$ & $0(\%)$ & $0(0 \%)$ \\
\hline & Others & $46(41 \%)$ & $46(34 \%)$ & $12(46 \%)$ & $22(63 \%)$ \\
\hline \multicolumn{2}{|c|}{ Total subject } & 107 & 131 & 26 & 35 \\
\hline \multicolumn{2}{|c|}{ Total ranking clauses } & 110 & 135 & 26 & 35 \\
\hline
\end{tabular}

The table 2 shows that the speakers and writers demonstrate how important of information which is related to the accident or to affirm information which is needed by society as a hearer or a reader. Besides, they endeavors to centre the information on the AQJ and who participates involve on it including his parents, Ahmad Dhani and Maya Estianti.

In short, the issues which are stated in text 1 , text 2 , and text 4 do not emphasize on the AQJ himself as the suspect, but they underline on the other participants who are involved on it. Its notion is supported by realizing Finite as a part of MOOD block.

Table 3 Finite Analysis of MOOD Block 


\begin{tabular}{cllcccc}
\hline \multirow{3}{*}{ Finite } & Temporal Finite & Present & $81(74 \%)$ & $118(87 \%)$ & $1(4 \%)$ & $20(57 \%)$ \\
\cline { 3 - 6 } & Verbal Operator & Past & $7(6 \%)$ & $3(2 \%)$ & $24(92 \%)$ & $9(26 \%)$ \\
\cline { 2 - 6 } & Future & $0(\%)$ & $0(\%)$ & $0(\%)$ & $3(8 \%)$ \\
\cline { 2 - 6 } & Finite Verbal Operator & $22(20 \%)$ & $14(10 \%)$ & $1(4 \%)$ & $6(17 \%)$ \\
\hline \multicolumn{2}{l}{ Total ranking clauses } & 110 & 135 & 26 & 35 \\
\hline
\end{tabular}

The table 3 shows that how the speakers and the writers convey the information by means that in text 1, 2, and 4 used present Finite Verbal Operator (FVO) as the dominance though text 4 consists of a written text as news report. Nevertheless, text 3 uses past FVO in delivering information. Indeed, the main purpose is, of those all, used to create proportion which is intelligible and arguable one. Besides, there are more others which contribute to an arguable argument that is RESIDUE as a part of clause structures.

RESIDUE is an element that brings high understanding of proposition. There are there parts of RESIDUE that are 'Predicator, Complement, and Adjunct'. First, Predicator is the lexical and content part of the verbal group, (Eggins, 1994: 161). Its function is to specify the kinds of process of the clause, (Halliday, 1985: 79 as cited in Eggins, 1994: 162). This shows that the speakers and the writers intend to deliver their information or some demand in order to emphasize it as the process of clauses. This is shown in table 4.

Table 4 Predicator Analysis of RESIDUE

\begin{tabular}{llcccc}
\hline & Types of Residue & Text 1 & Text 2 & Text 3 & Text 4 \\
\hline Predicator & Primary Tense & $26(24 \%)$ & $47(35 \%)$ & $6(15 \%)$ & $16(46 \%)$ \\
\cline { 2 - 6 } & $\begin{array}{l}\text { Secondary Tense (been }+\mathrm{V}_{\text {ing }} \\
\text { to })\end{array}$ & $1(1 \%)$ & $0(0 \%)$ & $0(0 \%)$ & $0(0 \%)$ \\
\cline { 2 - 6 } & Aspects and phrases $\left(\mathrm{V}_{\text {ing }}\right)$ & $1(1 \%)$ & $2(1 \%)$ & $1(4 \%)$ & $0(0 \%)$ \\
\cline { 2 - 6 } & $\begin{array}{l}\text { Voice of Clause } \\
\left.\text { (be }+\mathrm{V}_{3}\right)\end{array}$ & $20(18 \%)$ & $10(7 \%)$ & $4(15 \%)$ & $0(0 \%)$ \\
\hline Total predicator & 48 & 59 & 11 & 16 \\
\hline Total ranking clauses & 110 & 135 & 26 & 35 \\
\hline
\end{tabular}

Second, 'Complement' is a constituent which has potential to become a part of RESIDUE. It consists of nominal and adjectival groups. However, it is defined as nonessential participant in the clause, a participant somehow effected by the main argument of the proposition, (Eggins, 1994: 163). By observing the definitions and the results of analysis of 'Complement' that is $25 \%$ as the lowest and 49 percent as the highest of nominal groups and adjunctively group consists of two percent up to $11 \%$. It shows that the speakers and the writers add their information by setting nominal and adjectival groups as Complement to prove their argument by stating predicator and to produce some additional information or clarify the information interpersonally. It is illustrated in table 5.

Table 5 Complement Analysis of RESIDUE

\begin{tabular}{lcccc}
\hline \multicolumn{1}{c}{ Type of Complement } & Text 1 & Text 2 & Text 3 & Text 4 \\
\hline Nominal Group & $54(49 \%)$ & $35(26 \%)$ & $9(34 \%)$ & $22(63 \%)$ \\
Adjectival Group & $2(2 \%)$ & $15(11 \%)$ & $1(4 \%)$ & $2(6 \%)$ \\
& & & & \\
\hline Total complement & 56 & 50 & 10 & 21 \\
& & & & \\
\hline
\end{tabular}


Last, the last domain of RESIDUE is Adjunct. The use of adjunct in the four texts shows how important the information is the message delivering at the time of speaking or writing. It shows especially in the use of circumstantial, mood, and conjunctive adjuncts. The highest percentage those all is $54 \%$. While, the lowest one is $4 \%$. From the three adjuncts, circumstantial adjunct is the higher one than others. These expressions are as additional information, but it has no potential to elevate the modal of responsibility. It is regarded to what Halliday and Matthiessen (2004: 123) states that an adjunct is an element that has not got potential of being subject; that is, it cannot be elevated to the interpersonal status of modal responsibility. Those three adjuncts are shown in table 6.

Table 6 Adjunct Analysis of RESIDUE

\begin{tabular}{lcccc}
\hline Type of Adjunct & Text 1 & Text 2 & Text 3 & Text 4 \\
\hline Circumstantial & $50(45 \%)$ & $52(38 \%)$ & $15(50 \%)$ & $16(46 \%)$ \\
\cline { 2 - 5 } Mood & $24(22 \%)$ & $37(27 \%)$ & $1(4 \%)$ & $4(11 \%)$ \\
Comment & $1(1 \%)$ & $1(1 \%)$ & $0(0 \%)$ & $0(0 \%)$ \\
Polarity & $1(1 \%)$ & $0(0 \%)$ & $0(0 \%)$ & $0(0 \%)$ \\
Conjunctive & $43(39 \%)$ & $45(33 \%)$ & $11(42 \%)$ & $9(26 \%)$ \\
Continuity & $1(1 \%)$ & $1(1 \%)$ & $0(0 \%)$ & $0(0 \%)$ \\
Textual & $7(6 \%)$ & $5(4 \%)$ & $0(0 \%)$ & $0(0 \%)$ \\
\hline Total adjunct & 127 & 141 & 27 & 29 \\
\hline Total ranking clauses & 110 & 135 & 26 & 35 \\
\hline
\end{tabular}

To sum up, 'Mood Clouse Structure' can be interpreted that text 1 and 2, the speakers give an opportunity to respond to the events directly or indirectly. Text 3 and text 4 show that the writers slightly demand goods and services by focusing on producing information only. Deeply, the mood system especially Mood clause structure in the four texts, declarative clauses are the dominant. It is focused on giving information but not impossible the speakers or the writers demand respond or feedback.

\section{The Realization of Modality System in the Discourse of AQJ}

Modality refers to a range of different ways in which speakers can temper or qualify their message, (Eggins and Slide, 1997: p. 98). It has two components. They are EPISTEMIC modality or Modalization and DEONTIC modality or modulation. For each component, it categorizes into three levels that are high, median, and low levels.

The realization of both spoken and written texts is given in table 7 and 8 .

\section{EPISTEMIC modality or Modalization}

Table 7 Modalization Analysis of Modality System

\begin{tabular}{llcccc}
\hline \multirow{2}{*}{ Type of Modalization } & \multicolumn{4}{c}{ Percentage } \\
\cline { 2 - 5 } & & Text 1 & Text 2 & Text 3 & Text 4 \\
\hline \multirow{2}{*}{ Probability } & High & $2(2 \%)$ & $1(1 \%)$ & $0(0 \%)$ & $0(0 \%)$ \\
\cline { 2 - 5 } & Median & $10(9 \%)$ & $2(1 \%)$ & $0(0 \%)$ & $1(3 \%)$ \\
\cline { 2 - 5 }
\end{tabular}




\begin{tabular}{llcccc} 
& Low & $0(0 \%)$ & $4(3 \%)$ & $0(0 \%)$ & $0(0 \%)$ \\
\hline \multirow{2}{*}{ Usuality } & High & $0(0 \%)$ & $0(0 \%)$ & $0(0 \%)$ & $0(0 \%)$ \\
\cline { 2 - 6 } & Median & $0(0 \%)$ & $1(1 \%)$ & $0(0 \%)$ & $0(0 \%)$ \\
\cline { 2 - 6 } & Low & $0(0 \%)$ & $0(0 \%)$ & $0(0 \%)$ & $0(0 \%)$ \\
\cline { 2 - 6 } Total ranking & clauses & 110 & 135 & 26 & 35 \\
\hline
\end{tabular}

The results shown in the table 7, the realization of Modality system in the discourse of AQJ in the four texts shows that the highest percentage of 'Modalization' is the use of 'Median Probability'. It consists of 9\% and stated in text 1 as spoken language, and the lowest one is one percent. It means that the speaker expresses limited suggestion by means of demanding service of an institution and a listener or society related to the event itself. This is based on Eggins (1994: 180), 'Modalization' is the expression of the speakers' attitude towards what s/he's saying.

\section{DEONTIC modality or Modulation}

Table 8 Modulation Analysis of Modality System

\begin{tabular}{|c|c|c|c|c|c|}
\hline \multirow{2}{*}{\multicolumn{2}{|c|}{ Type of Modulation }} & \multicolumn{4}{|c|}{ Percentage } \\
\hline & & Text 1 & Text 2 & Text 3 & Text 4 \\
\hline \multirow[t]{3}{*}{ Obligation } & High & $16(14 \%)$ & $2(1 \%)$ & $1(4 \%)$ & $0(0 \%)$ \\
\hline & Median & $1(1 \%)$ & $0(0 \%)$ & $0(0 \%)$ & $3(8 \%)$ \\
\hline & Low & $0(0 \%)$ & $1(1 \%)$ & $1(4 \%)$ & $1(3 \%)$ \\
\hline \multirow[t]{3}{*}{ Inclination } & High & $0(0 \%)$ & $0(0 \%)$ & $0(0 \%)$ & $0(0 \%)$ \\
\hline & Median & $0(0 \%)$ & $0(0 \%)$ & $0(0 \%)$ & $0(0 \%)$ \\
\hline & Low & $0(0 \%)$ & $0(0 \%)$ & $0(0 \%)$ & $0(0 \%)$ \\
\hline Capability & Modulated & $6(5 \%)$ & $7(5 \%)$ & $2(8 \%)$ & $2(6 \%)$ \\
\hline \multicolumn{2}{|c|}{ Total ranking clauses } & 110 & 135 & 26 & 35 \\
\hline
\end{tabular}

The table 8 shows that there are three types of Modulation including obligation, inclination, and capability. However, of the four texts there are only obligation and capability. It means that both speakers and writers do not pay attention on the use of inclination even though the issue of AQJ needs more paying attention in order to reach the better life especially in improving teenagers' characters in doing social practices. Nevertheless, other types of modulation such as obligation and capability are intended to express in all texts.

The use of 'Modulation' is higher than 'Modalization'. It shows that the highest percentage is high obligation that is $14 \%$, and one percent is as the lowest one. Regarding to these results, Eggins (1994: 189) states that Modulation is a way for speakers to express their judgement or attitudes about action or events. It means that the speaker's judges on the one's attitude, and he demands services of a listener, whether a government or society like parents and others who are dealing with child protection in which they should care on their family especially children.

Indeed, the results of 'Modality System' analysis can be interpreted that the four texts propose listeners and readers to do their message.

The Realization of Appraisal System in the Discourse of AQJ 
The last domain of interpersonal meanings is appraisal system. Regarding to the definitions of appraisal system which are also declared by Eggins and Slade (1997), Freddi (2004), Martin and White (2005), Martin and Rose (2003) which are specified by Eggins and Slide that this system consists of four domains including appreciation, affect, judgement, and amplification, (Eggins and Slide, 1997: 124-38). Its function is used to negotiate our social relation, by telling our listeners or readers how we feel about things and people (in a word, what our attitudes are), (Martin and Rose, 2003: 26). Therefore, there are four types of appraisal system that are appreciation, affect, judgement, and amplification. These are shown in tables $9,10,11,12$, and 13.

Table 9 Appraisal System Analysis

\begin{tabular}{lcccc}
\hline \multirow{2}{*}{ Type of Appraisal } & \multicolumn{4}{c}{ Percentage } \\
\cline { 2 - 5 } & Text 1 & Text 2 & Text 3 & Text 4 \\
\hline Appreciation & $12(19 \%)$ & $7(12 \%)$ & $3(23 \%)$ & $9(37 \%)$ \\
Affect & $19(31 \%)$ & $28(49 \%)$ & $3(23 \%)$ & $5(20 \%)$ \\
Judgement & $21(34 \%)$ & $12(21 \%)$ & $6(46 \%)$ & $8(33 \%)$ \\
Amplification & $10(16 \%)$ & $10(17 \%)$ & $1(8 \%)$ & $2(8 \%)$ \\
\hline Total ranking sentence & 62 & 57 & 13 & 24 \\
\hline
\end{tabular}

The viewpoints of appraisal system bring the researcher to interpret the results of its analysis stated in the four texts: two are spoken texts and others are written ones. As result, the highest percentage of all texts is $49 \%$ stated in the use of judgement domain, and the lowest percentage is eight percent declared in the use of amplification constituent.

\section{a. Appreciation}

The first domain of appraisal systems is appreciation. Appreciation refers to how speakers evaluate a text (e.g. a painting, music, a work of literature) or a process (e.g. weather), (Eggins and Slide, 1997: 126). With appreciation we turn to meanings construing our evaluations of 'things', especially things we make and performance we give, but also including natural phenomena - what such things are worth (how we value them), (White, 2005: 56). They are given in table 10.

Table 10 Appreciation of Appraisal System Analysis

\begin{tabular}{|c|c|c|c|c|c|}
\hline \multirow{2}{*}{$\begin{array}{c}\text { Type of } \\
\text { Appreciation }\end{array}$} & \multicolumn{5}{|c|}{ Percentage } \\
\hline & & Text 1 & Text 2 & Text 3 & Text 4 \\
\hline \multirow[t]{2}{*}{ Reaction } & Positive & $6(50 \%)$ & $3(43 \%)$ & $0(0 \%)$ & $3(33 \%)$ \\
\hline & Negative & $1(8 \%)$ & $3(43 \%)$ & $0(0 \%)$ & $2(22 \%)$ \\
\hline \multirow[t]{2}{*}{ Composition } & Positive & $1(8 \%)$ & $1(14 \%)$ & $0(0 \%)$ & $0(0 \%)$ \\
\hline & Negative & $3(25 \%)$ & $0(0 \%)$ & $2(67 \%)$ & $1(11 \%)$ \\
\hline \multirow[t]{2}{*}{ Valuation } & Positive & $0(0 \%)$ & $0(0 \%)$ & $0(0 \%)$ & $0(0 \%)$ \\
\hline & Negative & $1(8 \%)$ & $0(0 \%)$ & $1(33 \%)$ & $3(33 \%)$ \\
\hline \multicolumn{2}{|c|}{ Total appreciation } & 12 & 7 & 3 & 6 \\
\hline \multicolumn{2}{|c|}{ Total ranking sentence } & 62 & 57 & 13 & 24 \\
\hline
\end{tabular}

\section{b. Affect}


The realization of affect in the discourse of AQJ shows feelings of all speakers and writers either unhappiness, in/secure, or dis/satisfied on the object of discussion. The results of affect analysis, it is useful to know people's feelings on an event, culture, and behavior.

\section{c. Judgement}

The realization of judgement in the discourse of AQJ shows how people comment and/or behave whether negative or positive jedgments of social sanction and social esteem. Of the four texts, they mostly use implied moral condemn and personal criticize in judging the object or AQJ and all participants involved in the collision.

\section{d. Amplification}

The last domain of amplification is mitigation. It is used to down-play or to mitigate speakers' personal expression, (Eggins and Slide, 1997:136). Regarding to the viewpoint and the results of analysis of mitigation, both speakers of text 1 and text 2 express their information by using some vague talk; however, the writers of text 3 and text 4 take attention in choosing words which are indicating vague ones.

Overall, Concerning on both the finding of analyzing appraisal systems, it can said that the speaker of text 1 is mostly dominant to emphasize his feeling about how people should and should not do. Besides, speaker of text 2 shows his emotion expressing high frequency of negative feeling of appreciation. Moreover, for judgement domain, the four texts, mostly speakers and the writers express their felling by giving high negative jadgement whether to the condition of collision of AQJ or others participants including to the event. Likewise, the percentages mostly prove that the speakers used especially in text 1 highly expressing vague of meaning especially in the realization of amplification in the discourse of $A Q J$ shows that speakers especially the speaker of text 2 set some portions of enrichment, mitigation, and mostly try to express augmenting as means to grade their words acceptable, but they produce vague talk as well. Additionally, the speakers and the writers express insecure on the condition of Indonesia nowadays especially the collision of AQJ.

\section{Conclusions}

In conclusion, it deals with the units of analysis including interpersonal meanings: mood, modality, and appraisal systems.

Mood system, by identifying clause structures of the four texts, we, readers or listeners, are able to interpret what is the purpose of communication whether offering or demanding (proposal), or giving information (proposition) especially between semantic organization of interaction and grammatical differences among speakers. Of the four texts, the speakers and the writers use full and elliptical declarative, interrogative; Yes/No polar and Wh-Content, and imperative: suggestions and command in delivering their message as spoken and written texts in order to create intelligible information.

Modality system, the realization of modalization and modulation the discourse of AQJ, the four texts especially spoken texts show that the speakers use modality in order to show 
the appropriate words used by speakers or the degree of judgements and attitudes on the collision of AQJ or what should do when facing a problem in undertaking social practices, then. Moreover, the writers present acceptable information to place themselves as writers as objective as possible.

Appraisal system, appreciation, affect, judgement, and amplification realized in the discourse of AQJ, uncovers the word choices of the speakers and the writers in appreciating the event, what they feel, how they judge or stating what people judge, and in grading and/or intensifying their message or information.

\section{REFERENCES}

Christie, F. 2002. Classroom Discourse Analysis: A Functional Perspective. New York: Continuum.

Creswell, J.W. 1994. Research Design: Qualitative and Quantitative Approaches. Loandon: SAGE Publication, Inc.

Eggins, S. 1994. An Introduction to Systemic Functional Linguistics. United Kingdom: Biddles Publishers Ltd.

Eggins, S. 2004. An Introduction to Systemic Functional Linguistics: 2nd Edition. London: Continuum.

Eggins, S, and Slade, D. 1997. Analyzing Casual Conversation. London: Cassell.

Freddi, M. 2004. Functional Grammar: An Introduction for the EFL Students: Bologna: Functional Studies for Non-Native Speakers of English.

Gerot, L, and Wilgnell, P. 1994. Making Sense of Functional Grammar. Australia: GerdStabler.

Halliday, M.A.K., and Matthiessen, C.M.I.M. 1999. Constructing Experience Through Meaning: Language Based Approach to Cognition. London and New York: Continuum.

Halliday, M.A.K., and Matthiessen, C.M.I.M. 2004. An Introduction to Functional Grammar: Third Edition. Great Britain: Arnold.

Martin, J.R., and White, P.R.R. 2005. The Evaluation of Language: Appraisal in English. New York: Palgrave Macmillan.

Palmer, F.R. 1986. Mood and Modality. Great Britain: Cambridge University Press.Schifrin, D., et al. 2001. The Handbook of Discourse Analysis. USA: Blackwell Publishers

Theodore, R. S. 2002. Th eSite of the Social: a Philosophical Account of the Constitution of Social Life and Change. United States of America: The Pennsylvania State University Press. Downloaded from http://dl.lux.bookfi.org/genesis.pdf.Accessed on November 21, 2013. 